\title{
Physiological and haematological parameters of bitches affected with pyometra
}

\author{
Basanti Jena, K. Sadasiva Rao, K. C. S. Reddy and K.B. P. Raghavender ${ }^{1}$
}

Department of Animal Reproduction Gynaecology and Obstetrics, College of Veterinary Science and Animal Husbandry, Sri Venkateswara Veterinary University, Rajendranagar, Hyderabad-30, Andhra Pradesh, India;

1. Department of Surgery and Radiology, College of Veterinary Science and Animal Husbandry, Sri Venkateswara Veterinary University, Rajendranagar, Hyderabad-30, Andhra Pradesh, India

Corresponding author: Basanti Jena email: drbasantijena@gmail.com

Received: 28-10-2012, Accepted: 10-12-2012, Published online: 18-04-2013

\section{How to cite this article:}

J ena B, Sadasiva Rao K, Reddy KCS and Raghavender KBP (2013) Physiological and haematological parameters of bitches affected with pyometra, Vet World 6(7): 409-412, doi: 10.5455/vetworld.2013.409-412

\begin{abstract}
Aim: The aim of the study was to find out alteration in physiological and haematological parameters in bitches affected with pyometra.

Materials and methods: Physiological and haematological parameters were studied in twenty eight bitches affected with pyometra.

Results: Evaluation of physiological parameters revealed that rectal temperature and respiration rate were increased in the bitches affected with pyometra where as heart rate did not reveal any significant change. In haematological parameters, haemoglobin, packed cell volume (PCV), total erythrocyte count (TEC) and lymphocyte count were decreased in the bitches affected with pyometra. The total leucocyte count (TLC), neutrophil count and monocyte count were increased in pyometra. Erythrocytic indices like mean corpuscular volume (MCV), mean corpuscular haemoglobin (MCH) and mean corpuscular haemoglobin concentration (MCHC) did not show any significant changes in the bitches.

Conclusion: Normocytic and normochromic anaemia, leucocytosis, a predominant absolute neutrophilia, lymphopenia and monocytosis were the most common findings in all the bitches affected with pyometra.
\end{abstract}

Key words: anaemia, bitch, leucocytosis, neutrophilia, pyometra

\section{I ntroduction}

Pyometra, a hormonally mediated acute or chronic polysystemic diestrual disorder was reported to induce high mortality in bitches if not treated [1]. It is recognized as one of the main causes of disease and death in the bitch [2]. It is a common disease in countries where routine spaying of young dogs is not common practice [3]. Physiological, haematological and biochemical changes in pyometra are considered significant to assess the severity of the disease condition [4]. In canine pyometra, the mean rectal temperature was elevated in all the bitches which clearly indicated septicaemia or bacteraemia and heart rate did not show any significant variation [5]. Circulatory abnormalities as evaluated by auscultation of heart sounds, pulse quality was found in bitches affected with pyometra [6]. The respiration rate was elevated in all the animals might be due to infection and toxaemia [5]. Low haemoglobin $(\mathrm{Hb})$ count along with low packed cell volume (PCV) value and low total erythrocyte count (TEC) was indicative of normocytic normochromic anaemia in the pyometra affected bitches [7]. In canine pyometra a mild normocytic,

This article is an open access article licensed under the terms of the Creative Commons Attribution License (http://creativecommons. org/licenses/by/2.0) which permits unrestricted use, distribution and reproduction in any medium, provided the work is properly cited. normochromic, non-regenerative anaemia is most frequently seen $[8,9]$ which progresses to a microcytic, hypochromic anaemia, when there is concurrent blood loss [10]. In bitches affected with pyometra, mean corpuscular volume (MCV) and mean corpuscular haemoglobin concentration (MCHC) remain within the normal range [11]. Leucocytosis characterized by absolute neutrophilia with a left shift [12], lymphopenia and monocytosis with no significant variation in Eosinophilic count are prominent blood picture in canine pyometra [5].

The aim was to study the changes in physiological and haematological parameters in bitches affected with pyometra.

\section{Materials and Methods}

The present work was carried out at Department of Animal Reproduction, Gynaecology and Obstetrics, College of Veterinary Science, Rajendranagar, Hyderabad.

Twenty eight clinical cases of different breeds in the age group of one to twelve years that were brought to the Animal Reproduction, Gynaecology and Obstetrics Unit, Teaching Veterinary Clinical Complex, Bhoiguda and Campus Hospital, College of Veterinary Science, Rajendranagar, Hyderabad with known breeding history or having clinical symptoms 
Table-1. Physiological and haematological parameters in different groups of bitches affected with pyometra

\begin{tabular}{lccccc}
\hline Parameters & Group I (0 day) & Group I (8th day) & Group II (0 day) & Group III (0 day) & Group IV(0 day) \\
\hline Physiological parameters & & & & & \\
Rectal temperature $\left({ }^{\circ} \mathrm{f}\right)$ & $102.83 \pm 0.28$ & $103.34 \pm 0.18$ & $103.2 \pm 0.28$ & $103.5 \pm 0.36$ & $102.94 \pm 0.35$ \\
Heart rate (Per minute) & $112.00 \pm 4.00$ & $109.86 \pm 2.23$ & $110.43 \pm 4.07$ & $107.28 \pm 4.00$ & $110.57 \pm 3.22$ \\
Respiration rate (Per minute) & $29.57 \pm 1.15$ & $32.00 \pm 0.90$ & $30.71 \pm 1.32$ & $29.86 \pm 1.75$ & $30.28 \pm 1.32$ \\
Haematological parameters & & & & \\
Haemoglobin (gram \%) & $11.0 \pm 0.32$ & $10.70 \pm 0.29$ & $11.08 \pm 0.38$ & $11.08 \pm 0.42$ & $11.10 \pm 0.28$ \\
PCV (\%) & $33.83 \pm 0.92$ & $33.30 \pm 0.90$ & $34.07 \pm 1.06$ & $34.24 \pm 1.18$ & $34.03 \pm 0.89$ \\
TEC ( $\left.\times 10^{6} / \mu l\right)$ & $5.48 \pm 0.17$ & $5.33 \pm 0.14$ & $5.54 \pm 0.89$ & $5.51 \pm 0.21$ & $5.51 \pm 0.14$ \\
MCV (fl) & $66.88 \pm 0.52$ & $66.77 \pm 0.51$ & $66.30 \pm 0.63$ & $66.44 \pm 0.77$ & $66.36 \pm 0.54$ \\
MCH (pg) & $21.44 \pm 0.32$ & $21.14 \pm 0.31$ & $21.91 \pm 0.48$ & $21.41 \pm 0.28$ & $21.13 \pm 0.47$ \\
MCHC (\%) & $31.48 \pm 0.27$ & $31.28 \pm 0.27$ & $31.34 \pm 0.40$ & $31.30 \pm 0.28$ & $31.64 \pm 0.41$ \\
TLC (? 10 $\left.{ }^{3} / \mu l\right)$ & $33.27 \pm 7.74$ & $34.14 \pm 7.76$ & $33.44 \pm 6.89$ & $36.63 \pm 9.58$ & $35.56 \pm 8.36$ \\
Neutrophil (\%) & $76.86 \pm 1.06$ & $78.00 \pm 0.97$ & $79.00 \pm 0.62$ & $79.57 \pm 1.02$ & $78.28 \pm 2.37$ \\
Lymphocyte $(\%)$ & $11.14 \pm 0.94$ & $10.00 \pm 0.92$ & $9.71 \pm 0.52$ & $8.86 \pm 0.74$ & $11.00 \pm 1.43$ \\
Monocyte $(\%)$ & $9.86 \pm 0.51$ & $10.28 \pm 0.52$ & $9.00 \pm 0.49$ & $9.00 \pm 0.31$ & $8.43 \pm 0.84$ \\
Eosinophil $(\%)$ & $2.14 \pm 0.40$ & $1.71 \pm 0.28$ & $2.28 \pm 0.18$ & $2.57 \pm 0.29$ & $2.28 \pm 0.28$ \\
\hline
\end{tabular}

suspected for open type of pyometra which was further confirmed by using diagnostic methods like abdominal palpation, radiography and ultrasound examination. Physiological parameters like rectal temperature, respiration rate and heart rate and haematological parameters like PCV, TEC, erythrocytic indices, TLC, neutrophil count, lymphocyte count, eosinophil count and monocyte count were studied in the affected bitches as per standard procedure before start of the treatment.

Bitches were divided into four groups each consisting of seven bitches and subjected to different treatment protocols. We have considered bitches in group for ease of record of parameters. The parameters of any group were not affected by any treatment because each parameter recorded before onset of treatment.

\section{Results}

In the present study, there was an increase in mean rectal temperature in pyometra affected bitches. However, 28.57 per cent bitches were having rectal temperature within normal range. The present study revealed that in 28.57 per cent of bitches TLC was found to be within normal range (< 17,000 cells). Leucocytosis was moderate $(17,000-30,000$ cells $)$ in 14.29 per cent of bitches, marked $(30,000-50,000$ cells $)$ in 42.85 per cent of bitches and extreme $(>50,000$ cells) in 14.29 per cent of bitches. The neutrophil count was found to be within normal range $(<77 \%)$ in 32.14 per cent of bitches. Neutrophilia was moderate (77-79\%) in 35.72 percent of bitches, marked (80-89\%) in 32.14 percent of bitches. The detail values of all physiological and haematological parameters are represented in Table-1.

\section{Discussion}

\section{Influence of pyometra on physiological parameters}

Influence of pyometra on rectal temperature: The findings of our study are in agreement with several reports $[1,13]$. Fever is a variable sign and associated with uterine inflammation and secondary bacterial infection as well as septicaemia or bacteraemia [14].
However, elevation in mean rectal temperature might be observed in 100 per cent bitches affected with pyometra $[5,15]$. In contrary to these studies, it has been reported that bitches with pyometra having toxaemia might actually be hypothermic [13]. The normal rectal temperature in some of the bitches in the present study might be due to chronic status of the disease.

Influence of pyometra on heart rate: The present study revealed that before treatment the mean heart rate was within normal range in all the four groups which is in accordance with the previous findings [5]. A total of five bitches $(17.85 \%)$ showed slightly increased heart rate which might be due to the effects of septicaemia or bacteraemia [6]. In contrary, it has been reported elevated pulse rate and tachycardia is found in all the pyometra affected bitches [15].

Influence of pyometra on respiration rate: In the present study, before treatment the mean respiration rate was increased in all the four groups might be due to infection and toxaemia [5]. However, shallow respiration rate was reported in bitches affected with pyometra [15].

\section{I nfluence of pyometra on haematological parameters}

Influence of pyometra on haemoglobin ( $\mathbf{H b}$ ): In the present study before treatment the mean haemoglobin level was decreased in the bitches affected with pyometra indicating anaemia which is in agreement with the previous reports $[4,5,7,16]$. This might be due to loss of red blood cells by diapedesis into uterine lumen apart from depressed feed intake and impaired erythropoiesis under toxaemic condition in severely affected cases [7]. Anaemia might be caused by toxic effects on the bone marrow, decreased erythrocyte viability and loss of erythrocytes to the uterine lumen in bitches affected with pyometra. An increased iron affinity by the reticuloendothelial system and a decreased total iron binding capacity is associated with acute and chronic inflammatory diseases and may also induce iron deficiency and subsequent anaemia $[5,16]$. However 17.86 percent of the pyometra affected 
bitches showed haemoglobin level within normal range might be due to concurrent dehydration [17]. In contrary, haemoglobin level was within the normal range in 100 per cent of the pyometra affected bitches [11].

Influence of pyometra on packed cell volume (PCV): In the present study before treatment the mean PCV level was decreased in the bitches affected with pyometra indicating a mild normocytic, normochromic and regenerative type of anaemia [7, 14]. However, in 17.86 per cent of bitches PCV level was found to be within normal range (PCV $>35 \%)$ which is in accordance with the previous reports [17] which might be due to concomitant dehydration [12]. In the present study anaemia (PCV < 35\%) was the most consistent finding among 82.14 per cent of the bitches which is higher than the report of 25 per cent affected bitches having PCV level less than 35 per cent [18]. In contrary, no change in PCV level in pyometra has also been reported [11].

Influence of pyometra on total erythrocyte count (TEC): In the present study the mean total erythrocyte count before treatment was decreased in the bitches affected with pyometra indicating anaemia [5, 7-10]. Normocytic, normochromic anaemia might be associated with the toxic depression of the bone marrow whereas severe non-regenerative, microcytic, hypochromic anaemia accompanied by extremely high white blood cell levels might be indicative of a concurrent blood loss possibly by diapedesis into the luminal pus and due to shortened life span of circulating erythrocytes associated with iron deficiency [17, 18]. The TEC level was found to be within normal range in 17.86 per cent of bitches. In contrary, no change in TEC level in pyometra has also been reported [11].

Influence of pyometra on erythrocytic indices: The present study revealed that the mean values of mean corpuscular volume (MCV), mean corpuscular haemoglobin $(\mathrm{MCH})$ and mean corpuscular haemoglobin concentration (MCHC) before treatment were within normal range in all the four groups indicating normocytic normochromic anaemia. These findings were in accordance with the previous reports of [11].

I nfluence of pyometra on total leucocyte count (TLC): In the present study, before treatment leucocytosis was the most consistent finding among the bitches affected with pyometra which was in agreement with the past reports $[5,7]$. This might be due to increased stress on the body defence mechanism which in turn produced increased leucocytes to combat the infection [5]. Prior to treatment the leucocytes were elevated indicating adequate bone marrow response in the bitches [19]. Normal leucograms with mild to moderate normocytic, normochromic anaemia (PCV: 30-35\%) might be due to the chronic nature of the disease and toxic suppression of the bone marrow [12]. Different degree of leucocytosis was observed in bitches affected with pyometra might be due to severity of the inflammation varying between animals [7].

I nfluence of pyometra on differential leucocyte count (DLC): In the present study, absolute neutrophilia with shift to left, lymphopenia, monocytosis with normal eosinophil count was the most consistent finding among the bitches affected with pyometra. Neutrophilia with regenerative shift to the left might be due to retention of purulent exudates in the uterus which exerts a chemotactic effect on neutrophils resulting into accelerated granulopoiesis and lymphopenia might be due to severe stress and elevated monocyte count might be due to chronicity of suppurative process $[4,5]$. Neutrophilia is a typical feature in haematology of bitches affected with pyometra [14,20,21] which might be due to influence of toxins in pyometra [22]. Absolute neutrophilia, lymphopenia, eosinophilia and monocytosis were common in pyometra [18, 23, 24]. However, neutrophilia with shift to left, lymphopenia with normal mean monocyte count, basophil count and eosinophil count were constant features of pyometra suggesting toxaemia [7].

\section{Conclusion}

Evaluation of physiological parameters revealed that rectal temperature and respiration rate were increased in the bitches affected with pyometra where as heart rate did not reveal any significant change. In haematological parameters, haemoglobin, packed cell volume (PCV), total erythrocyte count (TEC) and lymphocyte count were decreased indicating normocytic and normochromic anaemia in the bitches affected with pyometra. Leucocytosis with a predominant absolute neutrophilia, lymphopenia and monocytosis were consistently found in canine pyometra.

\section{Authors' contribution}

This article is the part of MVSc research work of the first author. All authors contributed equally in the whole research work as well as in the preparation of manuscript. All authors read and approved the final manuscript.

\section{Acknowledgements}

The authors are thankful to Sri Venkateswara Veterinary University, Tirupati for giving an opportunity to do the research. We wish to extend our thanks to the Dean, College of Veterinary Science, Rajendranagar, Hyderabad for providing all the facilities to complete the research successfully.

\section{Competing interests}

Authors declare that they have no competing interest.

\section{References}

1. Singh K. P., Singh B., Singh J. P., Singh S. V., Singh P. and Singh H. N. (2010) Diagnostic and therapeutic management of pyometra in bitches, Intas Polivet, $11: 86-87$. 
2. Coggan J. A., Melville P. A., Oliveira C. M., Faustino M., Moreno A. M. and Benites N. R. (2008) Microbiological and histopathological aspects of canine pyometra, Brazilian Journal of Microbiology, 39:477-483.

3. Pelander L., Hagman R. and Häggström J. (2008) Concentrations of cardiac Troponin I before and after ovariohysterectomy in 46 female dogs with pyometra, Acta Veterinaria Scandinavica, 50:35.

4. Singh S., Dadhich H. and Sharma G. D. (2006) Haematobiochemical studies in cystic endometrial hyperplasia pyometra complex in canine, Indian Journal of Veterinary Pathology, $30: 46-48$.

5. Nath K., Tiwari S. K. and Kalim O. (2009) Physiological and haematological changes in bitches with pyometra, Indian Vet. J., 86: 734-736.

6. Hagman R., Lagerstedt A. S., Hedhammar A. and Egenvall A. (2011) A breed-matched case-control study of potential risk-factors for canine pyometra, Theriogenology, 75:1251-1257.

7. Dabhi D. M., Dhami A. J., Parikh P. V. and Patil D. B. (2009) Comparative evaluation of haematological parameters in healthy and pyometra affected bitches, Indian Journal of Animal Reproduction, 30:70-72.

8. Feldman E. C. and Nelson R. W. (2004) Cystic endometrial hyperplasia and pyometra complex. In Kersey R (editor) Canine and feline endocrinology and reproduction, $\mathrm{W} \mathrm{B}$ Saunders Company, Philadelphia, London. pp. 852-67.

9. Troxel M. T., Cornetta A. M., Pastor Karen F., Hartzband L. E. and Besancon M. F. (2002) Severe Hematometra in a Dog With Cystic Endometrial Hyperplasia/Pyometra Complex, Journal of the American Animal Hospital Association, 38 : 85-89.

10. Greene C. E., Miller M. A. and Brown C. A. (1998) Pyometra and Cystic Endometrial Hyperplasia Complex, In : Infectious Diseases of Dog and Cat. W B Saunders Co, Philadelphia, London. pp.623-626.

11. Bigliardi E., Parmigiani E., Cavirani S., Luppi A., Bonati L. and Corradi A. (2004) Ultrasonography and Cystic Hyperplasia-Pyometra Complex in the bitch, Reproduction in Domestic Animal, 39: 136-140.

12. Verstegen J., Dhaliwal G., Onclin K. V. (2008) Mucometra, cystic endometrial hyperplasia, and pyometra in the bitch: Advances in treatment and assessment of future reproductive success, Theriogenology, 70:364-374.

13. Pretzer S. D. (2008) Clinical presentation of canine pyometra and mucometra: Areview, Theriogenology, 70:359-363.

14. Nelson R. W. and Feldman E. C. (1986) Pyometra, Veterinary Clinics of North America: Small Animal Practice, $16: 561-576$

15. Tiwari S. K., Roy S. and Dewangan R. (2004) Pyometra with endometrial hyperplasia in two Pomeranian bitches and its surgical management, Intas Polivet, 5 : 327-328.

16. Hagman R., Reezigt B. J., Ledin H. B. and Karlstam E. (2009) Blood lactate levels in 31 female dogs with pyometra, Acta Veterinaria Scandinavica, $51: 2$.

17. Schepper J. D., Stock J. V. D. and Capiau E. (1987) Anaemia and leucocytosis in one hundred and twelve dogs with pyometra, Journal of Small Animal Practice, 28 : 137-145.

18. Wheaton G., Johnson L., Parker J. and Kneller K. (1989) Results and complications of surgical treatment of pyometra. A Review of 80 cases, Journal of the American Animal Hospital Association, 25:563-568.

19. Arnold S., Hubler M., Casal M., Fairburn A., Baumann D., Flueckiger M. and Ruesch P. (1988) Use of low dose prostaglandin for treatment of canine pyometra, Journal of Small Animal Practice, 29:303-308.

20. Pande N., Prabhakar S., Gandotra V. K., Honparkhe M. and Nanda A. S. (2006) Efficacy of different techniques for diagnosis of pyometra in female dogs, Indian Journal of Animal Reproduction, $27: 31-33$.

21. Stephen R. J. and Robert G. (1994) Diseases of the Uterus, In Saunders Manual of Small Animal Practice. $1^{\text {st }}$ Edn. Mosby Year Book Publications. pp. 893-895.

22. Hagman R., Kindahl H. and Lagerstedt A. S. (2006) Pyometra in Bitches Induces Elevated Plasma Endotoxin and Prostaglandin $\mathrm{F}_{2} \alpha$ Metabolite Levels, Acta Veterinaria Scandinavica, $47: 55-68$.

23. Leib M. S. and Monnie W. E. (1997) Pyometra and cystic endometrial hyperplasia, In Practical Small Animal Internal Medicine. $1^{\text {st }}$ Edn. W B Saunders Company, Philadelphia, London. pp. 422.

24. England G. C. W., Freeman S. L. and Russo M. (2007) Treatment of spontaneous pyometra in 22 bitches with a combination of cabergoline and cloprostenol, Veterinary Record, 160 : 293-296.

$* * * * * * * *$ 